\title{
Introduction to the Special Issue
}

The solicitation of manuscripts for the special issue "Teacher Education to Prepare Aspiring Educators to Work with Diverse Students" began on March 1, 2020. We did not realize when we proposed this special issue how the events of the world would intersect to bring this topic to the forefront of debates about education, especially in North America. The coronavirus pandemic laid bare inequities in American education that had been ignored for decades. Students with special education needs, non-native English speaking students, students living in poverty or with limited technological access - all have found remote schooling during the pandemic to be problematic, if not impossible. How can we, as teacher educators, guarantee that aspiring teachers are working toward equitable access to education for all students?

Additionally, protests against systemic racism have continued across the United States and reached countless other countries - for most of 2020. Such protests have reflected larger conversations regarding the impact of racism throughout every corner of society including though certainly not limited to - school systems. Racism, for that matter, and its effects are pervasive in school systems. Most teachers, however, coming from the dominant race and culture, do not have a clear understanding of issues around race and how their privilege has played a role in their school success. How do we help them to see this and encourage them to work for justice? For the authors whose articles appear in this issue, these topics were not new. Because of this each manuscript provides a unique and practical perspective grounded in a widerange of experiences and deep understanding of many issues within the field of education.

We begin the special issue with articles presenting innovative ideas and approaches to teacher education coursework and fieldwork. In "Fighting the Plague: 'Difficult' Knowledge as Sirens' Song in Teacher Education", Cathryn Van Kessel and Muna Saleh explore ways to engage teacher education students in discussions of "difficult knowledge", those topics which may evoke defensiveness and indifference in students, by approaching these discussions with love, hope, and an appreciation for the humanity in all. Brittany Aronson, Rachel Banda, Ashley Johnson, Molly Kelly, Raquel Radina, Ganiva Reyes, Scott Sander, and Meredith Wronowski, in "The Social Justice Teaching Collaborative: A Collective Turn Towards Critical Teacher Education", described the use of a variety of frameworks - democratic education, critical pedagogy, critical race theory, critical whiteness studies, critical disability studies, and feminist and intersectionality theory - to create a cohesive view of social justice across three required education courses. In "Experience with Diversity is Not Enough: A Pedagogical Framework for 
Teacher Candidates that Centers Critical Race Consciousness", Alice Lee and Amos Lee describe how Critical Race Consciousness can be used to redesign and rethink methods courses and clinical fieldwork in teacher education programs. In "Contextualizing 'Practice': Helping Preservice Teachers Unpack Required Practices for Licensure", Rachel Moody explores a process for guiding preservice teachers to consider the ideological and sociopolitical discourse included in standards for teaching. This process is meant to create awareness of these ideas and bring to the attention of aspiring teachers the need to evaluate the practices that become the "standard".

Two articles explore the beliefs of aspiring teachers and how these beliefs may impact their teaching practice. Diana Wandix-White recounts discussions between a veteran AfricanAmerican teacher and a young, White pre-service teacher in her senior year of an undergraduate degree in education in "Care, Control, and Color: A Conversation about Disparities in School Disciplinary Practices". The two engage with one another around issues of race, discipline, and school, bringing together their lived experiences, questions, and understandings of the intersections of these topics. In "How Preservice Content Teacher Background Qualities Influence Their Attitude and Commitment to Supporting English Learners", Adam Agostinelli and Patrick McQuillan sought to determine whether preservice history teachers experiences being immersed in other language and cultures, as well as previous coursework on working with bilingual students, impacted their performance on tasks related to supporting bilingual learners in their future classrooms. Their findings suggested that preservice teachers with more experience with and exposure to cultural and linguistic diversity incorporate more teaching of language into their content area lesson plans.

The final three articles examine practices and methods that aspiring teachers could utilize to create more socially just and inclusive classroom spaces for all students. In "Think Outside the Book: Transformative Justice using Children's Literature in the Classroom", Divya Anand and Laura Hsu present a transformative justice approach to teaching children's literature. Examples of how to utilize a questionnaire for selecting books and facilitating discussions around identity markers such as race, poverty and socioeconomic status, religion, ethnicity and culture, hair diversity, immigrant status, language diversity, disabilities, sex and gender, sexual orientation, and family composition are explored. Deoksoon Kim and Fang Jia analyzed the creation of digital stories, an innovative pedagogical tool, created by three middle school bilingual students in "'Ever Wondered What Schizophrenia Was?': Three Bilingual Students' Digital Storytelling about Mental Disorders." These digital stories are evaluated as both texts and methods for discussing sensitive topics, such as mental health. In "Pathways to Becoming a Culturally Responsive Teacher: Narrative Inquiries into a Translanguaging Read Aloud", Stephanie Moody and Sharon Matthews recount the experiences of two undergraduate preservice teachers who each use a Spanish-language book in a read aloud to a predominantly Spanish-speaking group of children in an after school program for English learners. Both 
participants felt more confident in their teaching abilities after engaging in the read-alouds but differed in their reasons for embracing the use of translanguaging with bilingual students.

It is our hope that this collection of manuscripts will be helpful for K-12 teachers as well as teacher educators. Further, we hope that this work will contribute to the essential and ongoing conversations about how to provide equitable educational experiences for every student.

\section{Stephanie Garrone-Shufran}

Guest Editor

Merrimack College, School of Education and

Social Policy, North Andover, MA, USA

E-mail: garroneshufs@merrimack.edu

\section{Rory P. Tannebaum}

Guest Editor

Merrimack College, School of Education and

Social Policy, North Andover, MA, USA

How to cite: Garrone-Shufran, S, \& Tannebaum, R. P. (2020). Introduction to the special issue. Journal of Curriculum Studies Research, 2(2), i-iii. https://doi.org/10.46303/jcsr.2020.6 